\title{
Analysis of the Effect of China's Educational Fiscal Expenditure on Poverty Reduction Based on FGT Index*
}

\author{
Qian Li \\ School of Public Finance and Taxation \\ Zhongnan University of Economics and Law \\ Wuhan, China
}

\begin{abstract}
The role of poverty suppression in education is receiving increasing attention. According to the 1995-2017 China Rural Income Grouping Data, this paper uses the World Bank Povcalnet online poverty measurement tool to measure China's 1995-2017 FGT index including poverty breadth, poverty depth, and poverty intensity, and uses it as an indicator of poverty. The vector error correction model is used to empirically analyze the relationship between education fiscal expenditure and poverty breadth, poverty depth and poverty intensity. The results show that the fiscal expenditure of education has a significant inhibitory effect on the breadth of poverty. However, for the depth of poverty and the intensity of poverty, it has not exerted the inhibitory effect of application. On the contrary, it still has a positive effect on poverty to a certain extent. At the same time, economic growth remains the most important driving force for poverty reduction in China.
\end{abstract}

Keywords-FGT index; education fiscal expenditure; poverty reduction effect

\section{INTRODUCTION}

After more than 30 years of poverty alleviation and development and efforts, China has achieved brilliant results in anti-poverty. From 1978 to 2015, the cumulative poverty reduction exceeded 700 million people, and the poverty alleviation effect was remarkable. [1] However, with the deepening of poverty alleviation and the slowdown in poverty alleviation, China's poverty reduction is facing new challenges. Especially, poverty alleviation and povertyreturning are intertwined, and the problem of relative poverty has become increasingly prominent.

As one of the intervention-based poverty alleviation methods, education plays an important role in poverty alleviation. Education can directly improve people's income ability by upgrading human capital. At the same time, highquality educational poverty alleviation can block the intergenerational transmission of poverty, enhance the ability of the poor to sustain themselves, help maintain the effectiveness of poverty alleviation and prevent povertyreturning. Combined with the background of China's precise

*Fund: National Social Science Fund Youth Project "Study on the Two-way Influence Mechanism of Migrant Workers' Mobility and Health"; Project No.: 17CRK002 poverty alleviation, educational poverty alleviation also makes great sense.

There are many research results in the theoretical circles at home and abroad on the effects of educational poverty alleviation and poverty reduction effects. In the 1960s, Schultz, the founder of human capital theory, first proposed the concept of "poverty economics". He believed that "the poverty that still exists is largely the result of setbacks in human investment opportunities". From then on, education is linked to poverty reduction and poverty problem is officially brought into the field of educational research. [2]

With the deepening of relevant research, the relationship between education and poverty changes has mainly concentrated on two aspects:

The first is the theory of educational poverty alleviation. Just ss the name implies, the theory of educational poverty alleviation believes that education has an inhibitory effect on poverty changes. A large number of existing studies have confirmed this view, and Breton (2003) argues that human capital and physical capital are equally important in national income and economic growth. [3] Lin Boqiang (2005) conducts a comparative analysis of the rural poverty alleviation effects of various public expenditures in China The results confirmed that the poverty alleviation effect of education expenditure is the most significant. Education, especially basic education, is the most effective way to reduce poverty. [4] Tilak (2005) concludes that education and income poverty are negatively correlated in the analysis of poverty rates and different levels of schooling. [5] Otsuka's empirical analysis of the Philippines, Thailand, Bangladesh and India suggests that income from nonagricultural labor markets is decisive for poverty reduction, and that educational techniques have a decisive role in the acquisition of non-agricultural income. [6]

The second is education-caused poverty theory. The view is that education has exacerbated poverty or has little inhibitory effect on poverty, and education spending has become a new cause of poverty in rural areas. [7] [8] Fan Xianzuo (2008) discusses the reasons for the emergence of "education-caused poverty" from the perspective of comparative analysis of educational income and education 


\section{RESEARCH METHODS AND DATA SOURCES}

costs. He believes that this phenomenon has occurred due to the significant lag of educational income and the increasing nature of educational expenditure. [9] Yang Xiaomin (2007) also believes that family economic factors and high educational burden are the direct causes of educationinduced poverty. She also pointed out that the government's insufficient financial investment in education has also aggravated this phenomenon, and this phenomenon is analyzed from the perspective of government input. [10]

Based on two viewpoints, this paper argues that the "educational poverty alleviation" theory and the "educationcaused poverty" theory actually recognize the positive correlation between education and poverty alleviation, and believes that education is conducive to poverty alleviation. However, education-based poverty theory draws the conclusion that the role of education in curbing poverty is weakened, that is, the conclusion of "education-caused poverty" from the current overtop education burden, the asymmetry between education investment and education income, and the uncertainty of future education income. The focus of the two arguments can be attributed in fact to the differences in the impact of different educational input subjects on poor families and poor individuals. From the perspective of theory or reality, the main body of education investment can be divided into private or family as the main body and state finance as the main body, both of which are conducive to the slowdown of poverty. However, due to the particularity of educational products, there is a difference between the poverty reduction effect of taking family as the main body of educational investment and taking finance as the main body of educational investment. Relevant research believes that taking the state or finance investing as the main body of education will help to improve the efficiency of human capital accumulation, reduce inequality and promote faster economic growth, while taking the private investment as the main body of education will aggravate inequality. [11] The reason is that wealthy families will invest more educational resources in their children, while poor families don't have this condition, which ultimately affects the education of children from poor families. [12] Therefore, although the positive correlation between education and poverty alleviation is undoubted, the main role of education input has different effects on the role of poverty alleviation.

Therefore, considering that finance is currently the main mode of poverty alleviation, this paper directly analyzes the overall education financial expenditure, in order to analyze and judge the overall poverty reduction effect of the fiscal expenditure of education. Analysis of this issue is conducive to improving China's public education spending policy and giving full play to the poverty-suppressing role of educational products. At the same time, this paper will adopt the internationally accepted FGT index to measure the poverty level, and continue to decompose poverty into three indicators: poverty breadth, poverty depth and poverty intensity, and analyze the poverty alleviation effect of education fiscal expenditure.

\section{A. Poverty Determination Equation and Related Variables}

Drawing on the poverty equations of Lv Wei and Liu Chang (2008) [13], the poverty determination equation is established as follows:

$$
P O V=f(e d u, p g d p)
$$

(Equation 1)

The equation represents the determinants of poverty. The $P O V$ indicates the degree of poverty. This paper uses the three indicators of poverty breadth $(h)$, poverty depth ( $p g$ ), and poverty intensity ( $f g t$ ) to measure different poverty levels. $e d u$ represents investment in education and the indicator is measured by the state's fiscal education funding; $p g d p$ indicates economic growth, which is expressed in terms of per capita GDP.

Among them, the poverty degree $P O V$ is calculated by FGT index, and its Equation is as follows:

$$
\operatorname{FGT}(\alpha)=\frac{1}{N} \sum_{i=1}^{q}\left[\frac{z-y_{i}}{z}\right]_{(\text {Equation 2) }}^{\alpha}
$$

Among them, the $z$ is the poverty line, the $y_{i}$ is the income of poor population, the $N$ is the total population, the $q$ is the number of poor people, and the $\alpha$ indicates the sensitivity of poverty transfer, reflecting the extent to which the poor are deprived. The smaller the $\alpha$, the smaller the sensitivity, and the bigger the opposite.

$$
\text { When the } \alpha=0 \text {, the } F G T_{0}=\frac{q}{N}=h
$$
, that is, the poverty breadth indicator, reflects the change in the number of poor people;

When the $\alpha=1$, the $F G T_{1}=p g$, that is, the poverty depth indicator, reflects the distance between the income of the poor and the poverty line;

When the $\alpha=2$, the $F G T_{2}=f g t$, that is, the poverty intensity index, reflects the improvement or deterioration of the income distribution of the poor.

\section{B. Vector Error Correction Model}

A vector autoregressive model can be obtained by Equation (2). The vector autoregressive (VAR) model is based on the statistical properties of the data. Each endogenous variable in the system is a function of the hysteresis value of all endogenous variables in the system. It can better process multiple relevant economic indicators and 
If the $Y_{t}=\left(y_{1 t}, y_{2 t} \cdots y_{N}\right)^{T}$ is the $N \times 1$ order time

analyze and predict them. Its definition expression is as follows:

$$
Y_{t}=\sum_{i=1}^{p} \prod_{1} Y_{t-1}+\prod_{2} Y_{t-2}+\cdots+\prod_{p} Y_{t-p}+U_{t}
$$

$$
U_{t} \square \operatorname{IID}(0, \Omega)
$$

(Equation 3)

Among them, the $\prod_{i}(i=1,2, \cdots, p)$ is a $N \times N$ order matrix of the $i$ to be estimated; the $U_{t}=\left(u_{1 t}, u_{2 t}, \cdots, u_{N t}\right)^{T}$ is the $N \times 1$ order random error column vector; the $\Omega$ is the $N \times N$ order variance covariance matrix; $\mathrm{P}$ is the maximum lag order.

$$
\Delta Y_{t}=A_{1} \Delta Y_{t-1}+A_{2} \Delta Y_{t-2}+\cdots+A_{K-1} \Delta Y_{t-k+1}+\prod Y_{t-k}+U_{t}
$$

$$
\Delta Y_{t} \square I(0)
$$

Among them, the $\prod$ is the cointegration matrix; the $\prod Y_{t-k}$ $Y_{t-k}$ is the correction term matrix.

$$
\Delta Y_{t}=\alpha e c m_{t-1}+A_{1} \Delta Y_{t-1}+A_{2} \Delta Y_{t-2}+\cdots+A_{K-1} \Delta Y_{t-k+1}+\prod Y_{t-k}+U_{t}
$$

\section{(Equation 5)}

Among them, the $e c m_{t-1}=\beta^{\prime} y_{t-1}$ is the error correction term, which reflects the long-term equilibrium relationship between the variables; the $\alpha$ is the coefficient matrix, which reflects the speed of adjusting to the equilibrium state when the short-term deviates from the longterm equilibrium state, and here the coefficient is estimated to be negative. The remaining difference term coefficients reflect the short-term effects of short-term fluctuations of the variables on the explained variables.

\section{Data Source}

The sample interval selected in this paper is from 1995 to 2017. The data are all from the relevant years of China Statistical Yearbook, China Labor Statistics Yearbook, and China Education Funding Statistical Yearbook and so on. For the national financial education funding and per capita GDP, in order to eliminate the impact of price factors, the year of 1995 is taken as the base period, and the price index for removing inflation.

For the measurement index of poverty level, this paper measures rural poverty as a proxy variable to reflect the overall change of poverty in China. The calculation method is as follows: the data is based on China's income grouping data and is measured with the World Bank's povcalnet online poverty measurement tool. The data from 1995 to 1996 were measured by the 11 equal parts income group data of the relevant year's China Labor Statistics Yearbook combined with the survey population proportion; the 19971998 data were collected and calculated by the 20 equal parts income group data of the relevant year's China Labor Statistics Yearbook and the specific measurement method can refer to the method of Chen Lizhong (2007) to calculate the average value of each group, wherein $80 \%$ of the upper limit of the lowest income group is the group average of the lowest income group; the highest income group takes $130 \%$ of its lower limit as the group average of the highest income group. The average of the remaining groups is the average of the interval values, which is calculated based on the proportion of the surveyed population. The data for 20002017 is calculated by the five equal parts data of the per capita net income of rural households in the relevant years of China Statistical Yearbook. [14] When using povcalnet calculations, the poverty line criteria have a greater impact on the calculation results. In order to eliminate the technical impact of poverty line fluctuations on poverty measurement results, this paper draws on the majority of scholars' practice. Based on the 2010 national poverty line, this paper uses the consumer price index (CPI) for vertical removing inflation as the poverty line standard.

http://iresearch.worldbank.org/PovcalNet/PovCalculator.aspx 


\section{EMPIRICAL PROCESS}

In order to reduce the possible heteroscedasticity and uniform data magnitude, the relevant variables are processed by natural logarithm.

\section{A. Stationarity Test}

In order to avoid pseudo-regression, the time series data is first checked for stationarity to determine its stationarity and integration order. This paper uses the ADF test and the results are shown in "Table I":

TABLE I. ADF VARIABLE STATIONARITY TEST RESUlts

\begin{tabular}{|c|c|c|c|c|}
\hline Variable name & ADF statistic & $\begin{array}{c}\text { Inspection type } \\
(\mathbf{c}, \mathrm{t}, \mathrm{k})\end{array}$ & $\begin{array}{c}\text { Critical value } \\
(5 \%)\end{array}$ & Test result \\
\hline Lnh & -2.109 & $(\mathrm{c}, \mathrm{t}, 1)$ & -3.012 & Non-stable \\
\hline D. $\operatorname{lnh}$ & -6.701 & $(\mathrm{c}, \mathrm{t}, 0)$ & -3.645 & Stable \\
\hline Lnpg & -2.375 & $(\mathrm{c}, \mathrm{t}, 0)$ & -3.632 & Non-stable \\
\hline D.lnpg & -6.779 & $(\mathrm{c}, 0,0)$ & -3.012 & Stable \\
\hline Lnfgt & -2.849 & $(\mathrm{c}, \mathrm{t}, 0)$ & -3.633 & Non-stable \\
\hline D.lnfgt & -6.656 & $(\mathrm{c}, \mathrm{t}, 1)$ & -3.644 & Stable \\
\hline Lnedu & 2.791 & $(0,0,0)$ & -1.957 & Non-stable \\
\hline D.lnedu & -3.499 & $(\mathrm{c}, 0,0)$ & 3.012 & Stable \\
\hline Lnpgdp & -2.963 & $(\mathrm{c}, \mathrm{t}, 3)$ & -3.673 & Non-stable \\
\hline D.lnpgdp & -4.276 & $(\mathrm{c}, \mathrm{t}, 1)$ & -3.673 & Stable \\
\hline
\end{tabular}

As can be seen from the ADF test results in "Table I", the variable $\ln h, \ln p g, \operatorname{lnfgt}$, lnedu and $\ln p g d p$ at $1 \%$ and $5 \%$ of the significance level of the ADF statistics are greater than their corresponding critical value, which indicates that the variable is non-stable, and its corresponding first-order difference sequence is a stationary sequence, indicating that the difference sequence of these variables is a first-order single-order differential stationary sequence.

\section{B. Cointegration Test}

To establish a vector error correction model (VEC) for non-stationary time series, it is first necessary to verify whether there is a cointegration relationship between variables. The co-integration test requires that the variable be a single integer with the same whole order. According to the results in "Table II", all the variables in the model are firstorder and single-order, therefore, it is possible to perform cointegration analysis on variables. Since this paper involves more than two variables, this paper uses the Johansen cointegration test method.

Because the explanatory variables analyzed in this paper are poverty breadth $(h)$, poverty depth ( $p g$ ) and poverty intensity ( $f g t$ ), therefore, co-integration tests are performed on the three groups of lnh, lnedu, lnpgdp; lnpg, lnedu, lnpgdp; lnfgt, lnedu, and lnpgdp. The Johansen cointegration test results are shown in "Table II", "Table III", and 'Table IV":

The co-integration test of poverty breadth and education financial input and economic growth is shown in "Table II".

TABLE II. RESULTS OF JOHANSEN COINTEGRATION TEST BASED ON LNH

\begin{tabular}{cllll}
\hline Null hypothesis & Characteristic root & Trace statistics & $\mathbf{5 \%}$ critical value & $\lambda-\max ($ P value $)$ \\
\hline None $^{*}$ & 0.761441 & 44.74831 & 29.79707 & $28.663(0.0005)$ \\
At most 1 & 0.465810 & 16.08554 & 15.49471 & $12.540(0.0407)$ \\
At most 2 & 0.162449 & 3.545451 & 3.841466 & $3.545(0.0597)$ \\
\hline
\end{tabular}

According to the results of "Table II", there are two cointegration relationships between variables. Therefore, there is a long-term stable equilibrium relationship between the breadth of poverty and the fiscal expenditure of education.

In this paper, the standardized cointegration coefficient is estimated by EVIEWS9, and the cointegration equation which can accurately reflect the relationship between variables is selected. The cointegration equation of poverty breadth standardization is: 


$$
\ln h_{t}=-0.129 \ln e d u_{t}-0.288 \ln p g d p_{t}+7.088+e c m
$$

$(0.03614)$

[ 3.58022]
(0.06655)

[ 4.32029]

In Equation 6, ecm is the error correction term, the parentheses are the standard deviation, and the square brackets are the t values. It can be seen from Equation 6 that in the long run, both education financial input and economic growth have a significant inhibitory effect on the breadth of poverty. Specifically, the long-term poverty reduction flexibility of financial investment in poverty-producing education is -0.129 . For every one percentage point increase in education and financial input, the breadth of poverty will drop by 12.9 percentage points, and the statistical significance is significant; the long-term poverty reduction

\section{(Equation 6)}

flexibility of poverty growth to economic growth is -0.288 , indicating that for every percentage point increase in per capita gdp, the breadth of poverty will drop by 28.8 percentage points, which is statistically significant. This shows that the financial input of education is effective in reducing poverty, but in the long run, its poverty reduction effect is weaker than economic growth.

The co-integration test of the depth of poverty and the financial investment and economic growth of education is shown in "Table III".

TABLE III. RESULTS OF JOHANSEN COINTEGRATION TEST BASED ON LNPG

\begin{tabular}{cllll}
\hline Null hypothesis & Characteristic root & Trace statistics & $\mathbf{5 \%}$ critical value & $\lambda-\max$ (P value) \\
\hline None* & 0.738005 & 42.85695 & 29.79707 & $28.128(0.0009)$ \\
At most 1 & 0.468889 & 14.72896 & 15.49471 & $13.288(0.0650)$ \\
At most 2 & 0.066295 & 1.440482 & 3.841466 & $1.440(0.2301)$ \\
\hline
\end{tabular}

According to the results in "Table III", there is only one cointegration relationship between the variables, that is, there is a long-term stable equilibrium relationship between the depth of poverty and the fiscal expenditure of education.

$$
\ln p g_{t}=0.181 \ln e d u_{t}-0.287 \ln p g d p_{t}+3.278+e c m
$$

$[-4.13150]$

After estimating the cointegration coefficient after standardization, a cointegration equation for the standardization of poverty depth is established:

\section{$[-4.13150]$}

(Equation 7)

$$
\text { [2.69124] }
$$

The cointegration test of poverty intensity and education financial input and economic growth is shown in "Table IV".

TABLE IV. RESUlts OF JOHANSEN COINTEGRATION TEST BASED ON LNFGT

\begin{tabular}{cllll}
\hline Null hypothesis & Characteristic root & Trace statistics & $\mathbf{5 \%}$ critical value & $\lambda$ - $\max$ (P value) \\
\hline None $^{*}$ & 0.731015 & 42.71285 & 29.79707 & $27.575(0.001)$ \\
At most 1 & 0.476755 & 15.13778 & 15.49471 & $13.601(0.0565)$ \\
At most 2 & 0.070530 & 1.535955 & 3.841466 & $1.536(0.2152)$ \\
\hline
\end{tabular}

According to "Table IV", there is only one cointegration relationship between the variables, which also means that there is a long-term stable equilibrium relationship between the intensity of poverty and the fiscal expenditure of education.
After estimating the cointegration coefficient after standardization, the cointegration equation for establishing the poverty depth standardization is: 


\section{(Equation 8)}

Equations 7 and 8 show that there is a positive relationship between the financial investment of education and the depth of poverty and the intensity of poverty, and the statistical significance of the coefficient is significant. This shows that China's education financial investment has not played an active role in curbing the depth of poverty and the intensity of poverty; on the contrary, there is still a positive strengthening effect.

In summary, as the most important source of education poverty alleviation funds, there are differences in the effects of educational financial input on different types of poverty. From the results of the above cointegration equation, the education financial input has a significant positive effect on the poverty alleviation of the population near the poverty line; but it has little effect on the deep poverty population far from the poverty line, and even has a positive effect of strengthening the poverty. At the same time, the effect of improving the income distribution of the poor under the poverty line is not significant, and there is also a positive $D(\ln$

$\begin{array}{rrr}(0.53738) & (0.46170) & (0.28480) \\ {[-5.18030]} & {[3.09730]} & {[3.20902]}\end{array}$


$D(\operatorname{lnpg})=-0.848 * \mathrm{ecm}_{p g}-0.062 * D[\ln p g(-1)]$.

$\begin{array}{llll}(0.44251) & (0.29629) & (2.28705) & (0.44251) \\ {[-1.91628]} & {[-0.20995]} & {[-2.03997]} & {[-1.91628]}\end{array}$

$[-1.91628]$

$[-1.91628]$

[2.17882] (Equation 10)

$D(\ln f g t)=$

(2.62206)

[-0.73189]

[2.74719]

In Equation 9, 10 and 11, the parentheses are standard errors, and the square brackets are $t$ values.

It can be known from Equation 9, 10 and 11 that, firstly, the error correction term coefficients of the three equations are all negative, and at least the significance level of $10 \%$ passes the test, which is consistent with the inverse correction mechanism of the error correction model, indicating that the model has an error correction mechanism, which further proves that there is a long-term equilibrium relationship between variables; secondly, the magnitude of the error adjustment coefficient reflects the adjustment strength when deviating from the long-term equilibrium. The error adjustment coefficients of the three cointegration equations are $-2.784,-0.848$ and -1.101 , which indicates that for different types of poverty, the convergence rate of its return to the long-term equilibrium level is different. Among them, the correction of poverty breadth is the strongest. Third, in the short term, education financial input and per capita GDP have a downward pulling effect on poverty breadth, poverty depth and poverty intensity, but the effect is not significant. It is worth noting that the suppression of the breadth of poverty by the two periods of education finance investment is not only less effective than the financial investment of the first phase of education, but also the statistical significance is also increasing. This confirms that due to the characteristics of educational products, there is a certain time lag in the suppression of poverty by the financial investment of education.

\section{CONCLUSION}

This paper uses the national income grouped data of 1995-2017, uses the World Bank pvocalnet online poverty estimation software, calculates the poverty FGT index of China from 1995 to 2017, and further establishes a vector error correction model to empirically analyze the long-term equilibrium relationship between education fiscal expenditure, economic growth and poverty breadth, poverty depth and poverty intensity, as well as short-term dynamic effects. Based on the above empirical results, the following conclusions are drawn:

On the one hand, the fiscal expenditure of education effectively inhibited the occurrence of poverty breadth, but it did not have a positive effect on the depth and and the intensity of poverty. In order to achieve the optimal effect of education expenditure to reduce poverty, this paper proposes to optimize the structure of education financial expenditure

and attach importance to the investment of vocational education. For the poor, although basic education helps to improve their basic quality, long-term poverty alleviation and effective poverty alleviation also depend on the acquisition of effective life skills and vocational education is equipped with this function.

On the other hand, economic growth has a significant effect on poverty alleviation, indicating that economic growth has always been an important propeller for poverty reduction in China. This shows that economic growth not only helps to reduce the number of poor people, but also helps to improve the poverty situation of the population far from the poverty line, and at the same time, it also helps to improve the income distribution within the poor. This demonstrates that in the long run, economic growth is still the most important factor for poverty alleviation in China.

\section{REFERENCES}

[1] National Bureau of Statistics. Statistical Communique of the 2017 National Economic and Social Development of the People's Republic of China (in Chinese)

[2] Schultz, T.W., Investment in Human Capital. American Economic Review, Vol. 51, No.1,1961, pp.1-15

[3] Theodore $\mathrm{R}$ Breton. Can institutions or education explain world poverty? An augmented Solow model provides some insights. Journal of Socio-Economics. 2004,(33):45-69.

[4] Lin Boqiang. China's Government Public Expenditure and Poverty Reduction Policy [J]. Economic Research, 2005 (01): 27-37. (in Chinese)

[5] Tilak, J. B., Education and Poverty. Journal of Human Development, Vol.3, No.2,2002, pp.191-207.

[6] Otsuka K, Estudillo J P, Yamano T. The role of labor markets and human capital in poverty reduction: evidence from Asia and Africa [J]. Asian Journal of Agriculture \& Development, 2010, 7:23-40.

[7] Xin Meng, Robert Gregory, Youjuan Wang. Journal of Comparative Economics, 2005, Vol.33 (4), pp.710-729

[8] Wang Chengxin, Wang Gefang. New Poverty Factors and Radical Countermeasures in Rural China $[\mathrm{J}]$. Agricultural Modernization Research, 2003(05): 326-330. (in Chinese)

[9] Fan Xianzuo. Educational Economics [M]. Beijing: Renmin University of China Press, 2008. (in Chinese)

[10] Yang Xiaomin. The formation mechanism, causes and countermeasures of "education-caused poverty" [J]. Fudan Education Forum, 2007 (03): 36-40+48. (in Chinese)

[11] Glomm,G.,\& Ravikumar, B., Public versus Private Investment in Human Capital: Endogenous Growth and Income Inequality. Journal of Political Economy, Vol. 100, No,4,1992, pp. 818-834

[12] Lin Dishan, Zhang Xingxiang, Chen Yuhong. Whether public education investment can help alleviate population poverty - An 
Empirical Test Based on Multinational Panel Data [J]. Economics of finance and trade, 2016(08):34-49. (in Chinese)

[13] Lv Wei, Yang Mo, Wang Yan. Urban-rural income gap, urban-rural education inequality and government education investment [J]. Comparison of economic and social systems, 2015 (03): 20-33. (in Chinese)

[14] Chen Lizhong. Research on Urban Poverty Measurement in China's Transitional Period [D]. Huazhong University of Science and Technology, 2007. (in Chinese) 